\title{
APROVEITAMENTO DE RESÍDUO SIDERÚRGICO EM BLOCOS CerÂmicos Argilosos
}

\author{
UTILIZATION OF SOLID RESIDUE FROM SIDERURGICAL INDUSTRY IN \\ CLAY CERAMIC BLOCKS
}

\author{
Lorena Houri Machado Lima'; Simone Cristina dos Reis ${ }^{2}$ \\ Leonardo Ribeiro Borges ${ }^{3}$
}

1 Bacharel em Engenharia de Alimentos. Centro Universitário de Belo Horizonte, 2013. Departamento de Ciências Exatas. Belo Horizonte, MG. loryhmlima@hotmail.com.

2 Bacharel em Engenharia Química. Centro Universitário de Belo Horizonte, 2013. AngloGold Ashanti. Belo Horizonte, MG. sicristina.reis@yahoo.com.br.

3 Mestre. Universidade Federal de Minas Gerais, 2010. Professor do Centro Universitário de Belo Horizonte UniBH. Belo Horizonte, MG.leonardo.borges@prof.unibh.br.

Recebido em: 15/09/2013 - Aprovado em: 22/11/2013 - Disponibilizado em: 30/11/2013

RESUMO: Neste trabalho foi avaliada a incorporação de resíduo sólido, conhecido como fercoque, proveniente do setor siderúrgico, em massas argilosas para fabricação de cerâmica vermelha. Foram preparadas massas com os seguintes teores de resíduo: $0 ; 1,5 ; 3,0$ e 4,0\%. As composições de $0 \%$ foram submetidas à queima às temperaturas de 800, 900 e $1000{ }^{\circ} \mathrm{C}$, para determinar a temperatura ideal de queima. Em seguida, todas as composições foram queimadas à temperatura ideal de $900^{\circ} \mathrm{C}$, durante os períodos de $1 \mathrm{~h}, 1 \mathrm{~h} 30 \mathrm{~min}$ e $2 \mathrm{~h}$. As propriedades físicas e mecânicas foram determinadas em função do tempo de queima e da adição do resíduo. Os resultados obtidos indicaram que houve alteração nas propriedades dos corpos de prova, com a utilização do fercoque, revelando que o melhor tempo de queima foi de $2 \mathrm{~h}$ e a composição mais adequada para a produção de cerâmica vermelha foi de 3,0\%.

PalavRAS-CHAVE: Cerâmica. Massa Argilosa. Fercoque. Resíduo Siderúrgico

ABSTRACT: This work evaluated the incorporation of the solid siderurgical residue known as "fercoque" which comes from the siderurgical industry, in clay mass for the fabrication of red ceramic. Four different formulations were done in the ratio of 0,$15 ; 3$ and $4 \%$. The compositions of $0 \%$ were first burned under the temperatures of 800 , 900 and $1000^{\circ} \mathrm{C}$, in order to determine the ideal burning temperature for the main tests. Than, all the compositions were burned on de ideal temperature of $900^{\circ} \mathrm{C}$ for 1 hour, 1 hour and 30minutes and 2 hours. The physical and mechanical properties were determined in order of the burning time and the ratio of iron waste inserted on the formulation. The results indicated that there was an alteration on the properties of the samples due to the amount of iron waste used. revealing that the best burning time is of 2 hours and the most adequate formulation for the fabrication of red ceramic is of $3 \%$ of iron waste in the formulation.

KEYWORDS: Ceramic. Clay Mass. Iron Waste. Siderurgical Residue

\section{INTRODUÇÃo}

Os resíduos sólidos são uma crescente preocupação mundial devido ao seu grande volume e, também, à dificuldade de sua destinação final. Estes resíduos podem gerar custos adicionais e sérios problemas ambientais, causando a degradação do solo, 
contaminação do lençol freático e de outras fontes de água, além da contaminação do ar (OLIVEIRA; MACHADO; HOLANDA, 2004; PAIXÃO, 2005; PAIXÃO et al., 2008; VITORINO; MONTEIRO; VIEIRA, 2009). A incorporação de resíduos de várias atividades em produtos cerâmicos argilosos é uma alternativa tecnológica já utilizada, que pode contribuir para a redução do impacto ambiental (COSTA, 2011; MEDEIROS et al., 2010).

As siderúrgicas mineiras enfrentam problemas com as emissões atmosféricas, com os efluentes líquidos e, principalmente, com os resíduos sólidos. O resíduo sólido conhecido como pó do balão, retirado do coletor de resíduo gerado na saída de gases do alto-forno, é denominado de Charcoque, quando se utiliza o carvão vegetal (Charcoal em inglês) como agente redutor na queima do minério para a obtenção do metal purificado; Fercoque, quando se utiliza ferro; e Alucoque, ao se usar o alumínio. Esses materiais correspondem a $13 \%$ dos resíduos sólidos gerados nas indústrias siderúrgicas independentes.

Segundo o Projeto Minas Ambiente (1998), o pó do alto-forno consiste em material particulado carreado do forno pelos gases efluentes, retido em um sistema de limpeza a seco de gases, conforme mostrado na FIG. 1.

Conforme dados do Instituto Aço Brasil (2013), a indústria nacional produziu aproximadamente 34 milhões de toneladas de aço e 27 milhões de toneladas de ferro gusa em 2012. Minas Gerais, o maior produtor brasileiro de aço, contribuiu no mês de janeiro de 2013 com 921 mil toneladas, 32,7\% da produção nacional no mesmo período. A região de Sete Lagoas é uma das principais produtoras de ferro gusa, contribuindo com $29 \%$ da produção do estado (CALDEIRA et al., 2012).

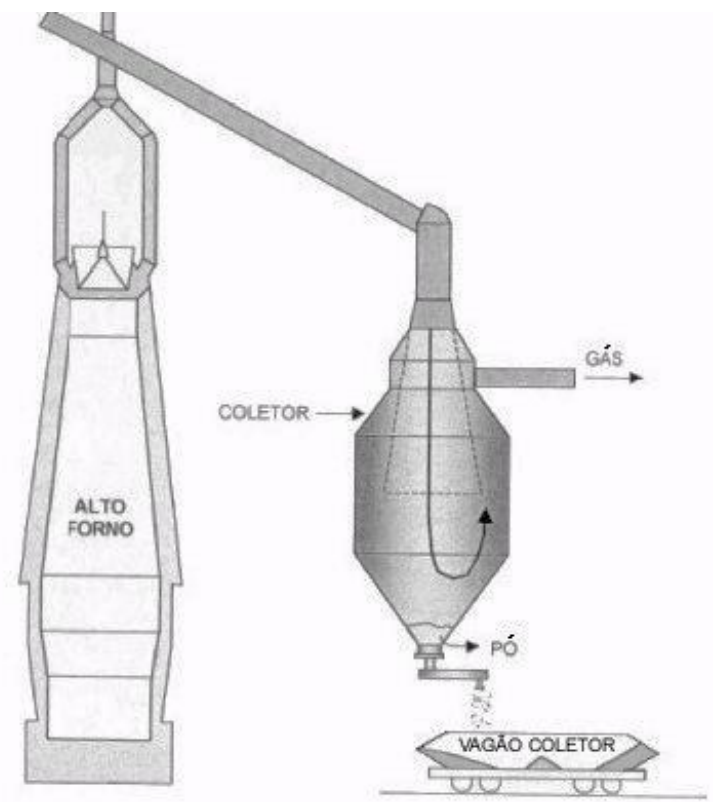

Figura 1 - Esquema de um coletor inercial de resíduo siderúrgico gerado na saída de gases do altoforno

$$
\text { Fonte - SILVA, 2007, p.12. }
$$

A produção de resíduo depende do processo siderúrgico em si e da eficiência do sistema de controle. Os produtores independentes no estado de Minas Gerais geram de 28 a $45 \mathrm{~kg}$ de resíduo por tonelada de gusa (MILANEZ; PORTO, 2008).

Segundo os mesmos autores, após sua coleta, cerca de $75 \%$ do resíduo total fica disposto nos pátios das empresas, a céu aberto, podendo se dispersar no meio ambiente, contaminando o $\mathrm{ar}$, águas e solo. A falta de políticas e diretrizes para o gerenciamento de resíduos sólidos industriais constitui um dos problemas ambientais mais graves, com o qual o setor siderúrgico tem se deparado nos últimos tempos.

A composição do material particulado proveniente do pó do alto-forno varia com o processo produtivo e com as matérias-primas empregadas. A composição química aproximada dos resíduos siderúrgicos é apresentada na Tabela 1. 
Tabela 1

Comparação das composições químicas de dois diferentes resíduos da indústria siderúrgica

\begin{tabular}{c|cc}
\hline Componente & $\begin{array}{c}\text { Fercoque } \\
\text { Teor (\%) }\end{array}$ & $\begin{array}{c}\text { Alucoque } \\
\text { Teor (\%) }\end{array}$ \\
\hline $\mathrm{Fe}_{2} \mathrm{O}_{3}$ & 57,94 & 2 \\
$\mathrm{SiO}_{2}$ & 12,41 & 15 \\
$\mathrm{CaO}$ & 5,82 & 2 \\
$\mathrm{Al}_{2} \mathrm{O}_{3}$ & 5,48 & 30 \\
$\mathrm{SO}_{3}$ & 2,23 & - \\
$\mathrm{K}_{2} \mathrm{O}$ & 0,63 & - \\
$\mathrm{MnO}$ & 0,62 & - \\
$\mathrm{ZnO}$ & 0,24 & - \\
$\mathrm{TiO}_{2}$ & 0,21 & - \\
\hline
\end{tabular}

Fonte - OLIVEIRA; MACHADO; HOLANDA, 2004, p.76. ALMEIDA; MELO 2001, p.09

$O$ presente trabalho tem 0 objetivo geral verificar a possibilidade de uso do resíduo fercoque na fabricação de blocos cerâmicos argilosos e os claros objetivos de:

-Especificar a quantidade ideal de resíduo para confeccionar os blocos;

-Identificar as caraterísticas físicas dos blocos;

-Comparar a resistência mecânica dos blocos acrescidos de resíduo com os blocos convencionais.

As seções subsequentes deste trabalho se compõem de uma breve descrição da produção de blocos cerâmicos, bem como da metodologia utilizada para a parte prática do trabalho e seus resultados.

\section{Metodologia}

A argila, matéria-prima para a produção de tijolo, é encaminhada ao caixão alimentador, sofrendo a primeira trituração. O material é transportado através de correia transportadora, passando por moinho de rolos e moinho de rosca. Após a adição controlada de água, a massa passa por mais dois moinhos, para se obter melhor fragmentação do material. A composição química aproximada da argila apresenta-se na Tabela 2.

Tabela 2

Composição química média da argila para produção de blocos cerâmicos

\begin{tabular}{c|c}
\hline Componente & Teor (\%) \\
\hline $\mathrm{SiO}_{2}$ & 54,9 \\
$\mathrm{Al}_{2} \mathrm{O}_{3}$ & 25,7 \\
$\mathrm{Fe}_{2} \mathrm{O}_{3}$ & 5,5 \\
$\mathrm{~K}_{2} \mathrm{O}$ & 2,2 \\
$\mathrm{TiO}_{2}$ & 0,69 \\
$\mathrm{Na}_{2} \mathrm{O}$ & 0,5 \\
$\mathrm{MgO}$ & 0,48 \\
$\mathrm{CaO}$ & 0,23 \\
$\mathrm{MnO}$ & 0,04 \\
$\mathrm{P}_{2} \mathrm{O}_{5}$ & 0,051 \\
\hline
\end{tabular}

Fonte - ALMEIDA; MELO, 2001, p.10. OLIVEIRA;

MARTINS, 2003

A etapa seguinte é a laminação, na qual é reduzida ainda mais a granulometria da argila, melhorando o acabamento final do produto. Em seguida, o material segue para a maromba, onde é comprimido, para que seja retirado todo $\mathrm{o}$ ar presente, e moldado, adquirindo o formato desejado do tijolo. Após essa etapa, o material passa por um cortador automático, separando cada bloco.

e-xacta, Belo Horizonte, v. 6, n. 2, p. 69-78. (2013). Editora UniBH. Disponível em: www.unibh.br/revistas/exacta/ 
O tijolo que sai da maromba precisa passar por um processo lento de secagem em estufa, antes de entrar no forno, para que não haja perda brusca de água.

Ao sair da estufa, o tijolo é encaminhado ao forno, para o processo de queima. O forno é constituído por bocas, por onde são adicionadas as lenhas. O sistema de exaustão permite que o fogo circule por todo o forno.

Ao final do processo de queima, os tijolos seguem para o pátio de armazenamento, onde estarão disponíveis para venda.

Alguns compostos presentes no fercoque proporcionam propriedades físico-químicas similares às da matéria-prima convencional, o que permite a sua incorporação na massa cerâmica. Exemplo disso é o ferro, proveniente do próprio minério, utilizado na produção de cerâmica, durante o processo de sinterização, acelerando a queima do material. Além disso, o ferro presente é oxidado a óxido férrico, o que garante a coloração avermelhada ao tijolo (BATISTA; NASCIMENTO; LIMA, 2008).

São encontrados na literatura estudos sobre a utilização de resíduos provenientes de diversas localidades para serem incorporados à massa cerâmica. Na região de Campos de Goytacazes, o resíduo sólido proveniente do setor siderúrgico foi incorporado à massa argilosa nas proporções de 0; 0,$5 ; 1,0 ; 1,5 ; 2,0 ; 2,5$ e 3,0\% em peso. Os corpos-deprova foram conformados por extrusão a vácuo e queimados nas temperaturas de 850, 900, 950, $1000 \mathrm{e}$ $1050 \stackrel{\circ}{\circ}$. Os resultados obtidos demonstraram que houve alterações nas características da massa cerâmica, ocorrendo uma redução da sua propriedade plástica, porém esta massa pode ser perfeitamente utilizada na fabricação de produtos de cerâmica vermelha (OLIVEIRA; HOLANDA, 2004).

Ribeiro (2011) também avaliou a adição de 3\% de charcoque, da Siderúrgica Metalsider Ltda.
(Betim/MG), em massa argilosa, proveniente do depósito de Cerâmica em Marabá (PA). Os corpos de prova foram submetidos à queima com a temperatura de $800 \stackrel{\circ}{\circ}$. Os resultados obtidos indicaram que a utilização do resíduo, nessa proporção, não alterou significativamente as propriedades físico-químicas da argila, sendo adequada a incrementação da massa argilosa com 3\% do resíduo para fabricação de blocos cerâmicos.

\section{Preparação do Corpo de prova para ENSAIOS LABORATORIAIS}

As amostras de argila foram coletadas em uma indústria ceramista da região metropolitana de Belo Horizonte - ICMBH, que cedeu também o fercoque, proveniente de uma siderurgia da região. Para a realização dos experimentos, foram utilizados laboratórios do Centro Universitário de Belo Horizonte - Uni BH - e o Laboratório de Materiais de Construção do SENAI Paulo de Tarso em Belo Horizonte, Minas Gerais.

As matérias-primas foram secas em estufa microprocessadora de secagem, marca Solotest, modelo Q317M-32, série 11090049, no Laboratório de Materiais e de Construção, a $110^{\circ} \mathrm{C}$, durante 2 horas.

As matérias-primas secas foram cominuídas, separadamente, em moinho martelo, de fabricação própria, localizado na Planta Piloto de Engenharia, onde foram reduzidas suas granulometrias, conforme apresentado na FIG. 2. Em seguida, foi realizada uma classificação granulométrica da argila e do fercoque, segundo a norma ABNT-NBR 7181:1984, através de uma série de peneiras Tyler de um agitador de peneiras, marca Solotest, modelo 1202230, série 5656, no Laboratório de Mecânica dos Solos. A série de peneiras utilizada foi de 200 a 48 mesh, em rotação de 15 rpm por 10 minutos. 


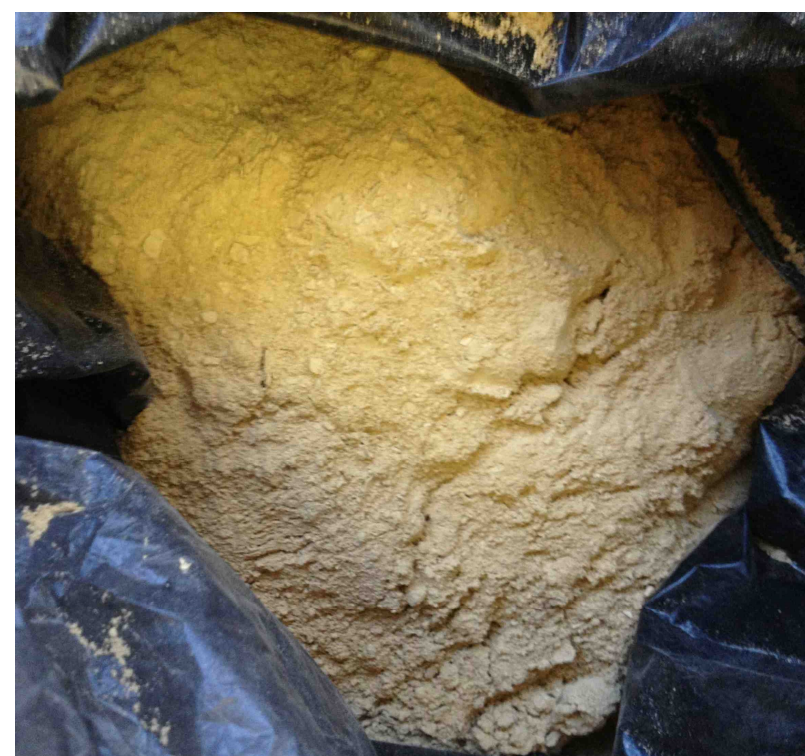

Figura 2 - Granulometria da argila, 35 mesh, utilizada na preparação das composições

Para a fabricação das massas argilosas, foram utilizadas partículas menores que 35 mesh, ou seja, com granulometria menor que $0,425 \mathrm{~mm}$, de argila e de fercoque. As matérias-primas foram pesadas em balança digital, marca Toledo, modelo 2098-23, série 10676210. As composições argilosas estudadas foram preparadas com adições de até $4 \%$ em peso de fercoque, conforme mostrado na Tabela 3.

As composições foram levadas a um misturador, marca VA Test, modelo VC370, durante 30 minutos, para que houvesse uma melhor homogeneização da massa.

Tabela 3

Composições residuais de fercoque nos diferentes blocos a serem estudados (\% peso)

\begin{tabular}{c|c|c}
\hline Composições & Argila & Fercoque \\
\hline C00 & 100,0 & 0,0 \\
C15 & 98,5 & 1,5 \\
C30 & 97,0 & 3,0 \\
C40 & 96,0 & 4,0 \\
\hline
\end{tabular}

Em seguida, as massas argilosas foram umedecidas, até atingirem umidade de $30 \%$, onde se obteve uma massa plástica adequada para extrusão.

Foram utilizados moldes quadrados de alumínio, com dimensões de $8 \times 8 \times 4 \mathrm{~cm}$, para confecção dos corpos de prova. Os moldes foram preenchidos com as massas argilosas e comprimidos, evitando a presença de espaços vazios nas massas. Posteriormente, fezse a remoção dos corpos de prova do molde, como mostra a FIG. 3.

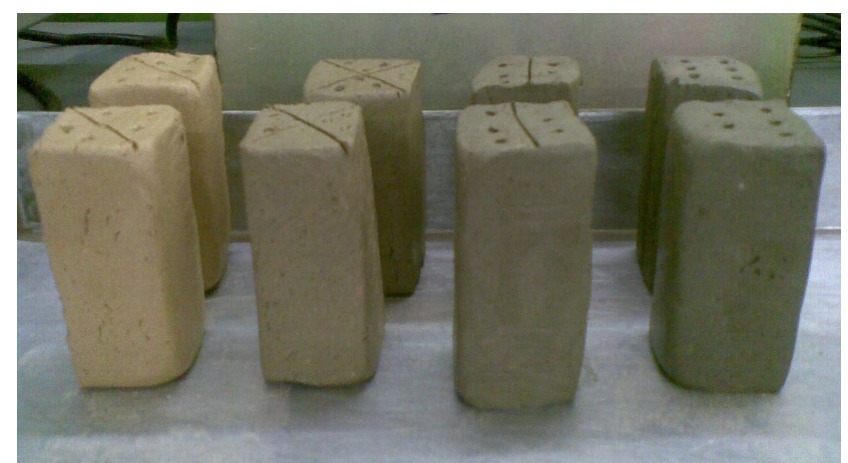

Figura 3 - Corpos de prova úmidos, com composições de $0 ; 1,5 ; 3,0$ e 4,0\%, a partir da esquerda

Os corpos de prova formam secos em estufa, marca Solotest, modelo Q317M-32, série 11090049, à temperatura de $110^{\circ} \mathrm{C}$, durante 24 horas, como demonstrado na FIG. 4. Após esse período, foi determinada a perda de massa à secagem dos corpos. Foi realizado um teste para determinar a temperatura ideal de queima, a $800^{\circ} \mathrm{C}, 900^{\circ} \mathrm{C}$ e 1000 ${ }^{\circ} \mathrm{C}$, com a composição C00. Para evitar choque térmico, o forno mufla foi aquecido $200 \stackrel{\circ}{\circ}$ a cada 30 minutos, até atingir a temperatura de queima. Após esse período, o forno foi desligado e mantido fechado, para que houvesse uma perda gradativa de temperatura do material, até a temperatura ambiente. Foi utilizado o forno mufla, marca Solotest, modelo M546V-14, no Laboratório de Bromatologia. Após a queima, os corpos foram submetidos ao teste de 
tensão de ruptura em uma Prensa Hidráulica, marca Solotest, modelo 1496220 , série 6431 , localizada no Laboratório de Materiais e de Construção.

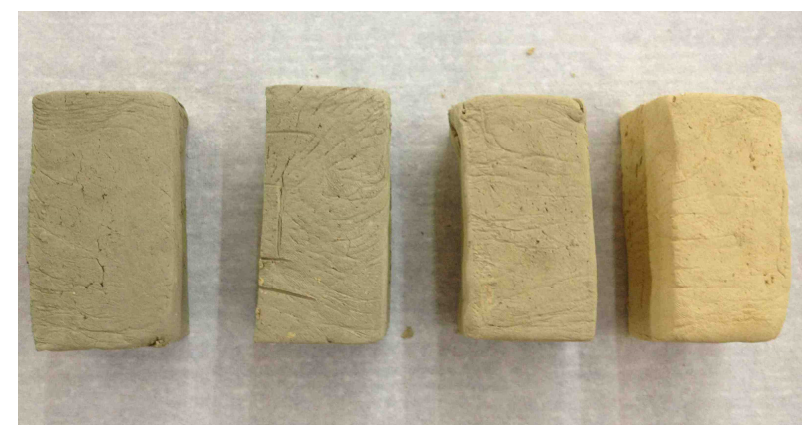

Figura 4 - Corpos de prova secos, com composições de 4,$0 ; 3,0 ; 1,5 ;$ e $0 \%$, a partir da esquerda

Uma vez estabelecida a temperatura ideal, os corpos de prova foram queimados durante os períodos de $1 \mathrm{~h}$, $1 \mathrm{~h} 30 \mathrm{~min}$ e $2 \mathrm{~h}$, nas mesmas condições de teste. Os blocos queimados estão apresentados na FIG. 5 .

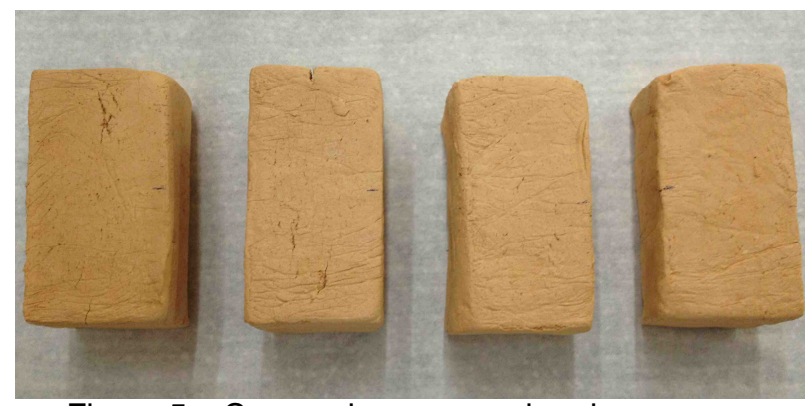

Figura 5 - Corpos de prova queimados, com composições de 4,0; 3,0; 1,5; e 0\%, a partir da esquerda

Após a queima, foram determinadas as seguintes propriedades dos materiais: perda de massa ao fogo, retração linear e tensão de ruptura, de acordo com a norma ABNT NBR ISO 5014:2012.
Para a realização do teste de carga de ruptura, os blocos foram enviados ao Laboratório de Materiais de Construção do SENAI Paulo de Tarso. Foi utilizada uma prensa hidráulica marca EMIC, modelo SSH 300, célula Trd 30.

Todos os testes foram realizados em triplicata.

\section{Resultados E discussão}

Os resultados do teste para definição da temperatura de queima com a composição C00 estão dispostos na tabela 4.

\section{Tabela 4}

Média dos resultados de perda de massa ao fogo e carga de ruptura das amostras do bloco $\mathrm{C00}$, em função de três diferentes temperaturas de queima

\begin{tabular}{c|ccc}
\hline $\mathrm{T}\left({ }^{\circ} \mathrm{C}\right)$ & $\begin{array}{c}\text { Perda de } \\
\text { massa ao } \\
\text { fogo }(\%)\end{array}$ & $\begin{array}{c}\text { Carga de } \\
\text { ruptura }(\mathrm{N})\end{array}$ & $\begin{array}{c}\text { Carga de } \\
\text { ruptura } \\
(\mathrm{Mpa})\end{array}$ \\
\hline 800 & 12,32 & 6367 & 1,230 \\
\hline 900 & 12,12 & 11400 & 1,573 \\
\hline 1000 & 12,52 & 5367 & 1,090 \\
\hline \multicolumn{4}{l}{ Legenda: T - temperatura }
\end{tabular}

De acordo com os resultados obtidos, verificou-se que os corpos submetidos à temperatura de queima 900 ${ }^{\circ} \mathrm{C}$ apresentaram melhor tensão à ruptura, identificando esta temperatura como a ideal.

Deu-se então prosseguimento ao restante dos testes. Os resultados do experimento estão apresentados na tabela 5. 
Tabela 5

Médias dos resultados de tempo de queima, perda de massa à secagem, perda de massa ao fogo, retração linear e carga de ruptura dos corpos de prova, a $900^{\circ} \mathrm{C}$ durante $1 \mathrm{~h}, 1 \mathrm{~h} 30$ e $2 \mathrm{~h}$.

\begin{tabular}{c|cccccc}
\hline $\begin{array}{c}\text { Corpos de } \\
\text { prova }\end{array}$ & $\begin{array}{c}\text { Tempo de } \\
\text { queima }\end{array}$ & $\begin{array}{c}\text { Perda de } \\
\text { massa à } \\
\text { secagem (\%) }\end{array}$ & $\begin{array}{c}\text { Perda de } \\
\text { massa ao } \\
\text { fogo (\%) }\end{array}$ & $\begin{array}{c}\text { Retração linear } \\
\text { de queima (\%) }\end{array}$ & $\begin{array}{c}\text { Carga de } \\
\text { ruptura (N) }\end{array}$ & $\begin{array}{c}\text { Carga de } \\
\text { ruptura (MPa) }\end{array}$ \\
\hline \multirow{3}{*}{ C00 } & 2h & 35,52 & 12,04 & 4,98 & 7438,22 & 5,44 \\
& $1 \mathrm{~h} 30$ & 35,48 & 11,98 & 4,63 & 8209,59 & 6,02 \\
& 1h & 34,23 & 14,41 & 2,79 & 5840,38 & 4,27 \\
C15 & 2h & 34,99 & 12,61 & 4,98 & 10744,09 & 7,85 \\
& $1 \mathrm{~h} 30$ & 35,06 & 12,55 & 5,18 & 10413,51 & 7,61 \\
& $1 \mathrm{~h}$ & 34,27 & 14,32 & 2,62 & 5619,98 & 4,11 \\
C30 & 2h & 34,80 & 13,21 & 3,56 & 6501,55 & 4,75 \\
& $1 \mathrm{~h} 30$ & 34,74 & 13,28 & 6,88 & 4408,35 & 3,23 \\
& $1 \mathrm{~h}$ & 34,46 & 14,89 & 1,62 & 4343,54 & 3,22 \\
C40 & 2h & 34,80 & 13,65 & 3,47 & 3801,76 & 2,74 \\
& $1 \mathrm{~h} 30$ & 34,81 & 13,70 & 5,27 & 3471,17 & 2,54 \\
& $1 \mathrm{~h}$ & 34,40 & 15,25 & 3,00 & 5234,30 & 3,74 \\
\hline
\end{tabular}

A queima tende a reduzir as dimensões do material. A FIG. 6 apresenta o comportamento da retração linear de queima das diferentes composições estudadas.

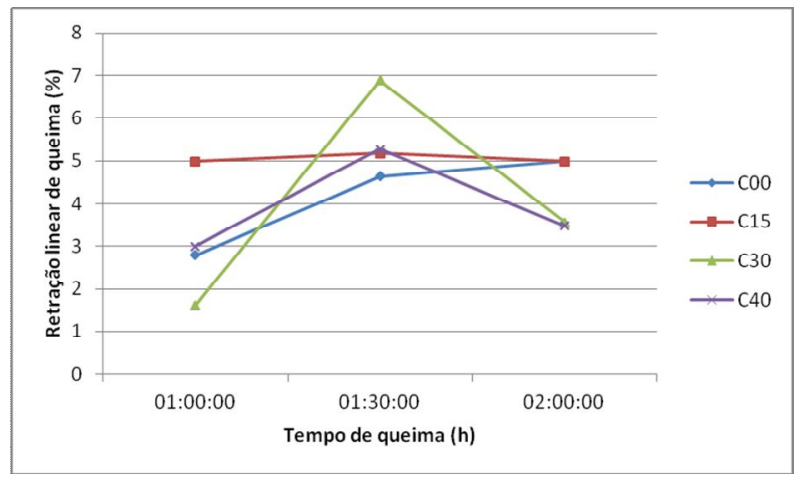

Figura 6 - Retração linear de queima das diferentes composições em função da temperatura de queima

É possível observar que em todas as composições com incrementação do resíduo, há uma maior retração linear na queima durante $1 \mathrm{~h} 30 \mathrm{~min}$. As composições queimadas por $1 \mathrm{~h}$ tiveram medidas de retração linear muito variadas, e durante a queima de $2 \mathrm{~h}$ todas as composições tiveram uma retração menor ou igual ao bloco cerâmico puro.

A retração linear das composições tende a aumentar ligeiramente, com o crescimento do resíduo, devido à sua natureza não plástica.

A análise dessa propriedade é importante durante a elaboração de um projeto, para que não ocorram problemas futuros de dimensionamento dos blocos.

A perda ao fogo fornece informações relativas à presença de matéria orgânica e materiais voláteis no material (DIAS et al.). A análise é representada pela FIG. 7. 


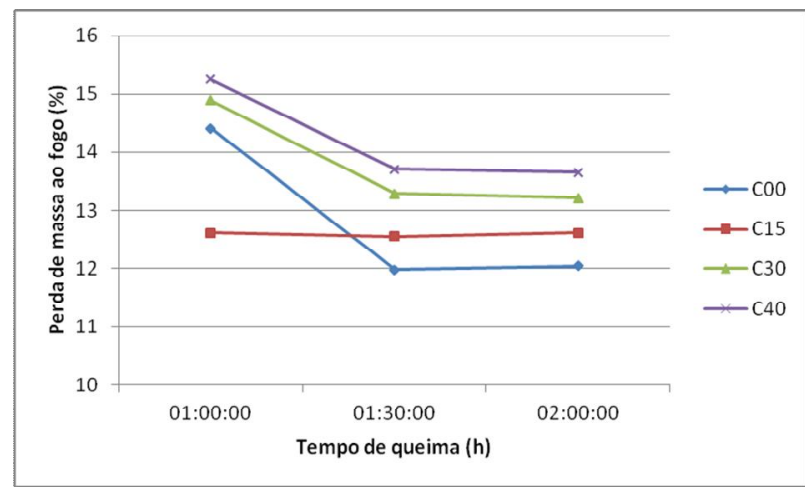

Figura 7 - Perda de massa ao fogo das diferentes composições em função da temperatura de queima

Durante a queima de $1 \mathrm{~h}$, nota-se a maior perda percentual desses componentes, quando comparados à queima por $1 \mathrm{~h} 30 \mathrm{~min}$ e $2 \mathrm{~h}$. Segundo os dados, durante esses 2 últimos períodos, praticamente não há perda de matéria orgânica e materiais voláteis.

Com exceção da composição C15, queimada durante $1 \mathrm{~h}$, à medida que se aumenta a incorporação do resíduo na massa argilosa tem-se um aumento da perda de massa ao fogo.

Os valores encontrados para tensão de ruptura das composições C00, C30 e C40 estão dentro dos limites aceitáveis para a fabricação de cerâmica estrutural, 0,5 a 7,0 MPa (OLIVEIRA; HOLANDA, 2004).

Com a incorporação do resíduo em maiores quantidades, é observada uma redução na tensão de ruptura do material, como demonstram as composições C30 e C40, evidenciadas na FIG. 8. Isso indica que a adição do resíduo deixa os corpos menos densos, devido ao aumento da sua porosidade aparente, o que diminui a resistência do bloco, necessitando de maior cuidado no manuseio.

A composição $\mathrm{C} 15$ apresentou uma tensão de ruptura superior à da massa argilosa pura, porém acima da especificação, em todos os tempos analisados.

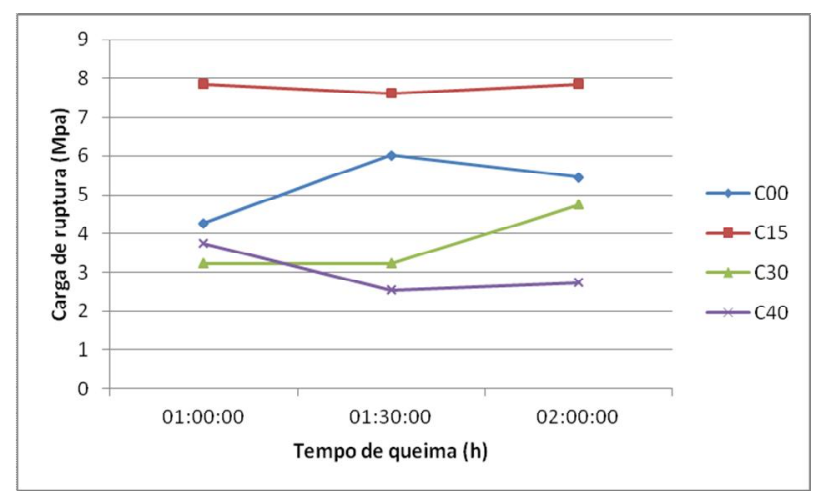

Figura 8 - Carga de ruptura das diferentes composições em função da temperatura de queima

Os resultados apresentados demonstram que a queima das composições pelo período de $1 \mathrm{~h}$ não é suficiente para manterem constantes as propriedades do material, apesar da adição de fercoque, resíduo com grande teor de $\mathrm{Fe}_{2} \mathrm{O}_{3}$, o que aumenta a temperatura de queima, diminuindo o tempo de permanência do bloco no forno. Isso é evidenciado por uma queima incompleta, como mostrado na FIG.9, e pela perda ao fogo, que se estabiliza após a queima por $1 \mathrm{~h} 30$ e 2h. Além disso, a análise de tensão de ruptura sugere melhor resistência dos blocos incrementados com o resíduo, quando queimados durante $2 \mathrm{~h}$, como apresentado na FIG. 10.

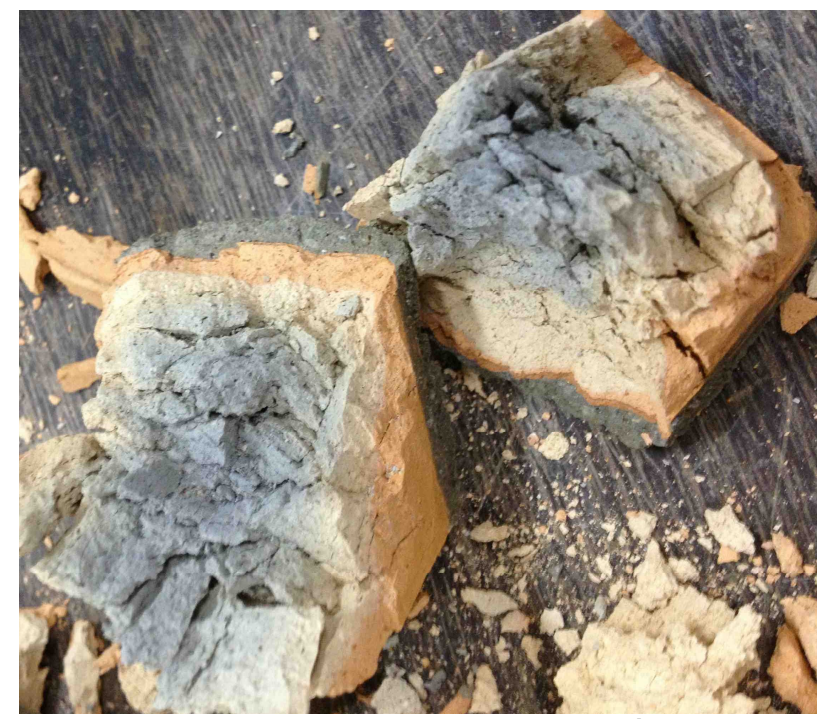

Figura 9 - Bloco queimado durante $1 \mathrm{~h}$, após o teste de carga de ruptura 


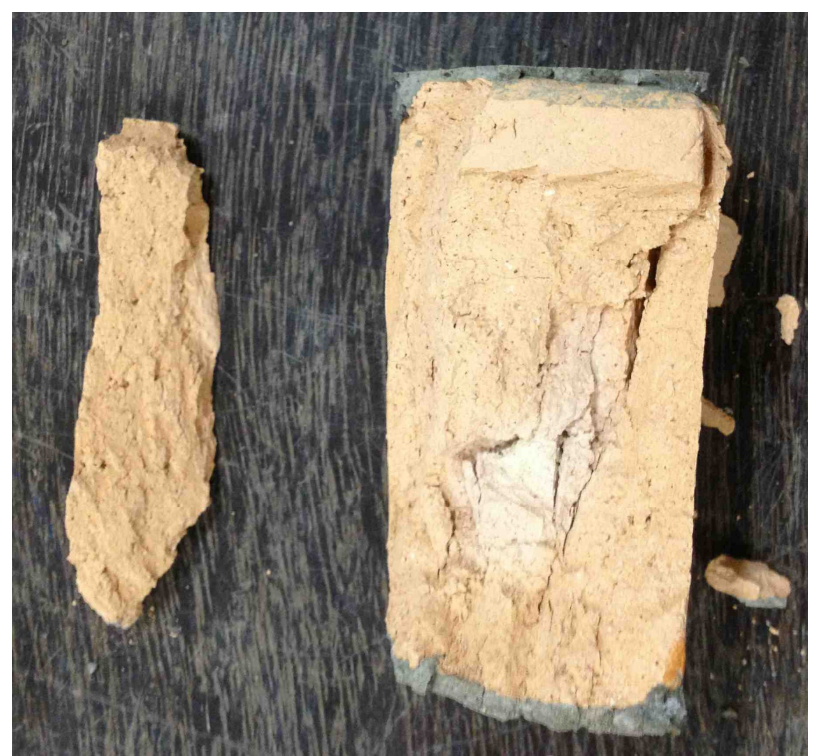

Figura 10 - Bloco queimado durante 2h, após o teste de carga de ruptura argilosa se mostrou a mais adequada, por apresentar um valor de tensão à ruptura mais elevado e dentro das especificações. A adição de $4,0 \%$ do resíduo causou uma queda significativa da resistência do material.

\section{AGRADECIMENTOS}

Os autores agradecem à Operadora Ceramista Ltda., ao Professor MSc. Mateus Justino da Silva, coordenador do laboratório de Materiais de construção do UniBH, e à equipe do laboratório de materiais de construção do SENAI Paulo de Tarso.

\section{CONCLUSÃo}

Ao se avaliar cada composição, fica claro que a adição de fercoque na proporção de $3,0 \%$ na massa

\section{REFERÊNCIAS}

ABNT-NBR 7181:1984: Solo - Análise granulométrica (1984).

ABNT-NBR ISO 5014:2012: Produtos refratários conformados densos e isolantes - Determinação do módulo de ruptura à temperatura ambiente (2012).

ALMEIDA, M. L. B.; MELO, G. C. B. Alternativas de usos e aplicações dos resíduos sólidos das indústrias independentes de produção de ferro- gusa do estado de minas gerais. In: 21. .9 CONGRESSO BRASILEIRO DE ENGENHARIA SANITÁRIA E AMBIENTAL. Anais..., João Pessoa, PB, p. 1-13, set. 2001.

BATISTA, V. R.; NASCIMENTO, J. J. S.; LIMA, A. G. $B$. Secagem e queima de tijolos cerâmicos maciços e vazados incluindo variações dimensionais e danos estruturais. Revista Eletrônica de Materiais e Processos, Campina Grande, v.3.1, p.46-61, 2008. Disponível em <http://www.dema.ufcg.edu.br/revista/index.php/REMA P/article/viewFile/64/89>. Acesso em 06 nov 2012. ISSN 1809-8797.
BRASIL, MINAS GERAIS. Ministério Público do Estado de Minas Gerais. Procuradoria Geral de Justiça. CEAT - Centro de Apoio Técnico. SISCEAT 7700485. ID 463217. Belo Horizonte, 05 mar 2009.

CALDEIRA, D. C. D et al. Omissão de Nutrientes e Atividade Enzimática em Solo de Cerrado Adicionado de Pó de Balão e Cultivado com Milho. In: FERTBIO, 2012, Maceió. A responsabilidade socioambiental da pesquisa agrícola. Disponível em < http://ainfo.cnptia.embrapa.br/digital/bitstream/item/67 746/1/Omissao-nutrientes.pdf>. Acesso em 09 mar 2013.

COSTA, A. J. C. Análise de viabilidade da utilização de lodo de ETA coagulado com o cloreto de polialumínio (PAC) composto com areia como agregado miúdo em concreto para recomposição de calçadas: Estudo de caso na ETA do município de Mirassol-SP. 2011. 155 f. Dissertação de Mestrado (Engenharia Hidráulica e Saneamento) - Escola de Engenharia de São Carlos, Universidade de São Paulo (USP), São Carlos, Fev. 2011. 
DIAS, L. M. et al. Alternativa de destinação final do lodo de Estação de Tratamento de Água Fabricação de blocos cerâmicos. Goiás. Disponível em

<http://www.bvsde.paho.org/bvsAIDIS/PuertoRico29/di as.pdf>. Acessos em 03 jun. 2013.

INSTITUTO AÇO BRASIL. Disponível em <http://www.acobrasil.org.br/site/portugues/numeros/e statisticas.asp>. Acesso em 10 mar 2013.

MEDEIROS, E. N. M. et al. Incorporação de cinza de lenha, lodo de estação de tratamento de água e cinza de casca de arroz em massa cerâmica: utilização da técnica de planejamento. Cerâmica, São Paulo, v. 56, n. 340, dez. 2010, p.399-404. Disponível em <http://www.scielo.br/scielo.php?script=sci_arttext\&pid =S0366-69132010000400014\&lng=pt\&nrm=iso $>$.

Acesso em: 15 out. 2012. http://dx.doi.org/10.1590/S0366-69132010000400014.

MILANEZ, B.; PORTO, M. F. S.; A ferro e fogo: impactos da siderurgia para o ambiente e a sociedade após a reestruturação dos anos 1990. In: IV ENCONTRO NACIONAL DA ANPPAS, 2008, Brasília. Disponível em http://www.anppas.org.br/encontro4/cd/ARQUIVOS/G T6-61-8-20080509163054.pdf>. Acesso em 10 mar 2013.

OLIVEIRA, E. M. S.; HOLANDA, J. N. F. Influência da adição de resíduo (lodo) de estação de tratamento de águas nas propriedades e microestrutura de cerâmica vermelha. Cerâmica, São Paulo, v. 54, n. 330, jun. 2008 Disponível em <http://www.scielo.br/scielo.php?script=sci_arttext\&pid $=$ S0366-69132008000200006\&lng=pt\&nrm=iso $>$.

acessos em $15 \quad$ out. 2012. http://dx.doi.org/10.1590/S0366-69132008000200006.

OLIVEIRA, G. E.; HOLANDA, J. N. F. Reaproveitamento de resíduo sólido proveniente do setor siderúrgico em cerâmica vermelha. Cerâmica, São Paulo, v. 50, n. 314, dez. 2004. Disponível em <http://www.scielo.br/scielo.php?pid=S0366-

$69132004000200002 \&$ script $=$ sci_arttext $>$. Acessos em 01 mar. 2013.

OLIVEIRA, E. M. S.; MACHADO, S. Q.; HOLANDA, J. N. F.. Caracterização de resíduo (lodo) proveniente de estação de tratamento de águas visando sua utilização em cerâmica vermelha. Cerâmica, São Paulo, v. 50, n. 316, dez. 2004, p.324-330. Disponível em

<http://www.scielo.br/scielo.php?script=sci_arttext\&pid =S0366-69132004000400007\&lng=pt\&nrm=iso >.

$\begin{array}{lllll}\text { Acessos } & \text { em } & 09 & \text { out. } & 2012\end{array}$ http://dx.doi.org/10.0990/S0366-69132004000400007
OLIVEIRA, M. R. C.; MARTINS, J. Caracterização e classificação do resíduo sólido "pó do balão", gerado na indústria siderúrgica não integrada a carvão vegetal: estudo de um caso na região de Sete Lagoas/MG. Quím. Nova, São Paulo, v. 26, n. 1, Jan. 2003 Available from $<$ http://www.scielo.br/scielo.php?script=sci_arttext\&pid $=$ S0100-40422003000100002\&lng=en\&nrm=iso >.

Access on $14 \quad$ Mar. 2013. http://dx.doi.org/10.1590/S0100-40422003000100002.

PAIXÃO, L. C. C. Aproveitamento de Lodo de Estação de Tratamento de Água em Cerâmica Vermelha. 2005. 81 f. Dissertação de Mestrado (Caracterização e Seleção de Materiais) - Escola de Engenharia e Redemat, Universidade Federal de Ouro Preto (UFOP), Ouro Preto, Fev. 2005.

PAIXÃO, L. C. C. et al. Efeito da incorporação de lodo de ETA contendo alto teor de ferro em cerâmica argilosa. Cerâmica, São Paulo, v. 54, n. 329, mar. 2008, p.63-76. Disponível em $<$ http://www.scielo.br/scielo.php?script=sci_arttext\&pid $=$ S0366-69132008000100010\&lng=pt\&nrm=iso $>$.

Acessos em $15 \quad$ set. 2012. http://dx.doi.org/09.1590/S0366-69132008000100010.

PROJETO MINAS AMBIENTE, Pesquisa Tecnológica para Controle Ambiental em Unidades Independentes de Produção de Ferro-Gusa: Diagnóstico, CDTN/ CETEC/ FEAM/ UFMG, Belo Horizonte, 1998.

RIBEIRO, E. D. L. Estudo comparativo entre sistemas de limpeza de gases de alto-forno em siderúrgicas não-integradas a carvão vegetal e alternativa de reaproveitamento do pó do balão. 2011. 78 f. Tese de Doutorado (Tecnologia Mineral) Escola de Engenharia, Universidade Federal de Minas Gerais (UFMG), Belo Horizonte, Abr. 2011.

SILVA, C. S. W. Avaliação ambiental decorrente do uso agrícola de resíduos do sistema de limpeza de gases de uma indústria siderúrgica a carvão vegetal. 2007. 98 f. Dissertação de Mestrado (Fitotecnia) - Universidade Federal de Viçosa (UFV), Viçosa, 2007.

VITORINO, J. P. D.; MONTEIRO, S. N.; VIEIRA, C. M. F.. Caracterização e incorporação de resíduos provenientes de Estação de Tratamento de Água em cerâmica argilosa. Cerâmica, São Paulo, v. 55, n. 336, dez. 2009, p.385-392. Disponível em $<$ http://www.scielo.br/scielo.php?script=sci arttext\&pid $=$ S0366-69132009000400008\&lng $=$ pt\&nrm $=$ iso $>$.

Acessos em $13 \quad$ out. 2012. http://dx.doi.org/10.1390/S0366-69132009000400008. 